\title{
Investigation on Effect of Aged Pumped-Storaged Component Replacement on Economic Profits Considering Reliability and Economic Efficiency
}

\author{
Jong Sung $\mathrm{Kim}^{1, *}$ \\ ${ }^{1}$ Sunchon National University, Suncheon, Republic of Korea \\ *Corresponding author. Tel: +82 617503537, Fax: +82 617503530, E-mail:kimjsbat@sunchon.ac.kr
}

\begin{abstract}
Recently, availability decrease due to increase of midnight electric power demand has risen necessities to improve economic efficiency of the pumped-storage power plants in South Korea. The necessities cause to extend a preventative maintenance cycle, especially an overhaul cycle. But, unconditional extension cannot be implemented because it may generate unanticipated failures due to insufficient maintenance. So, first, in this study, possibility of extension of the preventative maintenance cycle is identified via investigation on preventative maintenance situation of overseas and domestic hydropower plants. Second, a methodology to optimize the preventative maintenance cycle considering both reliability and economic efficiency is presented via review of the previous reliability studies and considering characteristics of the pumped-storage power plant. The methodology consists of the eight parts including selection of principal components and subcomponents, identification of damage mechanisms in the principal components/subcomponents, FMEA(failure mode effect analysis), derivation of replacement and repair time of the principal components/subcomponents, design of preventative maintenance cycle plan, reliability analysis, economic assessment, and derivation of the optimized preventative maintenance cycle. Also, as a result of application of the methodology to an aged pumped-storage power plant in South Korea, the overhaul cycle has been extended from 4 years to 7.5years. Last, effect of replacement of some aged principal subcomponents such as rotor runner and generator stator on economic profits is investigated via application of the methodology to the aged pumped-storage power plant.
\end{abstract}

Keywords: Pumped-Storage Power Plants, Replacement, Preventative Maintenance, Reliability, Economic Efficiency

\section{Introduction}

Recently, it has been reported that availability of pumped-storage power plants decreases due to increase of midnight electric power demand in South Korea[1]. This low availability has been risen necessities to improve economic efficiency of the pumped-storage power plants. The necessities cause to extend a preventative maintenance cycle, especially an overhaul cycle. But, unconditional extension cannot be implemented because it may generate unanticipated failures due to insufficient maintenance.

All over the world, some studies has been performed about life extension, modernization and preventative maintenance of hydro and pumped-storage power plants[2-12]. In South Korea, life extension and modernization methodology for hydro power plants was established and applied to the aged hydro power plants several years ago but the methodology to optimize systematically an overhaul cycle wasn't developed[2]. The previous studies didn't investigate effect of aged pumped-storaged component replacement on economic profits considering reliability and economic efficiency.

Therefore, first, in this study, possibility of extension of the preventative maintenance (overhaul) cycle is identified via investigation on preventative maintenance situation of overseas and domestic hydropower plants[3-8]. Second, a methodology to optimize the preventative maintenance cycle considering both reliability and economic efficiency is presented via review of the previous reliability studies[6,9-12] and considering characteristics of the pumped-storage power plant. Also, the optimized overhaul cycle is derived via application of the methodology to an aged pumped-storage power plant in South Korea. Last, effect of replacement of some aged principal subcomponents such as rotor runner and 
generator stator on economic profits is investigated via application of the methodology to the aged pumped-storage power plant.

\section{Investigation of Preventative Maintenance Situation}

Table 1 presents the preventative maintenance cycles of hydro or pumped-storage power plants in some countries[3-8]. A class means complete overhaul for all components and B class means partial overhaul for some components. From the table, it is found that the preventative maintenance cycles of pumped-storage power plant in South Korea are shorter than those of other countries. It is identified that the A class preventative maintenance cycles of TEPCO and J-POWER have been gradually increased from 6years and will be 15years in the future by interview with working staff of TEPCO and J-POWER[7]. Also, It is confirmed that the recent availability of pumped-storage power plants in Japan is less than $10 \%$ similarly with South Korea. In some cases, Japan industries have taken and repaired the damaged principal components such as turbine runner, guide vane and generator rotor at maker's fabrication shops out of the site during A class overhaul period in order to improve their reliability to level of new products, but South Korea industries have repaired all the damaged principal components at the site.

As a result of this investigation, it is possible to extend the A class preventative maintenance cycle of pumped-storage power plants in South Korea like Japan. But, it is necessary to review in more detail and extend sequentially the cycle in order to extend to 10 15 years because there is difference in preventative maintenance method between South Korea and Japan.

Table 1. Preventative maintenance cycles of South Korea and overseas pumped-storage power plants.

\begin{tabular}{|c|c|c|c|c|c|}
\hline \multicolumn{3}{|c|}{ Classification } & \multirow{2}{*}{$\begin{array}{c}\text { A Class Preventative } \\
\text { Maintenance Cycle (years) }\end{array}$} & \multicolumn{2}{|c|}{ StandardPeriod(days) } \\
\hline $\begin{array}{l}\text { South Korea/other } \\
\text { countries }\end{array}$ & Company & $\begin{array}{c}\text { Power } \\
\text { Plant }\end{array}$ & & A & B \\
\hline \multirow{5}{*}{$\begin{array}{c}\text { South Korea: } \\
\text { pumped- } \\
\text { storage[3] }\end{array}$} & A & $\mathrm{L}$ & 4(A-B-A) & 80 & 18 \\
\hline & B & $\mathrm{M}$ & 4(A-B-B-A) & 76 & 12 \\
\hline & $\mathrm{C}$ & $\mathrm{N}$ & $5(\mathrm{~A}-\mathrm{B}-\mathrm{A})$ & 80 & 18 \\
\hline & $\mathrm{D}$ & $\mathrm{O}$ & 4 6(A-B-B-B-A) & 80 & 16 \\
\hline & $\mathrm{E}$ & $\mathrm{P}$ & $4(\mathrm{~A}-\mathrm{B}-\mathrm{A})$ & 80 & 18 \\
\hline \multirow{2}{*}{$\begin{array}{l}\text { South Korea: } \\
\text { hydro }\end{array}$} & KHNP[4] & - & 4(A-B-A) & - & - \\
\hline & K-Water[5] & - & $5(\mathrm{~A}-\mathrm{B}-\mathrm{A})$ or $6(\mathrm{~A}-\mathrm{B}-\mathrm{B}-\mathrm{A})$ & - & - \\
\hline $\begin{array}{l}\text { Japan : hydro } \\
\text { including } \\
\text { pumped- } \\
\text { storage[6] }\end{array}$ & - & - & $\begin{array}{l}\text { 9 15 or depends on } \\
\text { equipment condition }\end{array}$ & - & - \\
\hline \multirow{2}{*}{$\begin{array}{l}\text { Japan : pumped- } \\
\text { storage[7] }\end{array}$} & TEPCO & Tamhara & 12 18(20,000hours) & $150 \sim 180$ & $21 \sim 28$ \\
\hline & J-Power & Okki & 15 & 125 & $8 \sim 10$ \\
\hline $\begin{array}{l}\text { USA: pumped- } \\
\text { storage[8] }\end{array}$ & - & - & Average 10 (5 16) & 75 150 & - \\
\hline
\end{tabular}

\section{Review of the Previous Studies about Reliability Assessment}

Fig. 1 shows an optimization result of Snowy Mountains Hydro-electric Authority[9] for the complete overhaul cycle of hydro power plants by using the commercial program, RCM Turbo[13]. As shown in the figure, cost of unplanned maintenance increases drastically due to increase of breakdown probability with time span between planned activity while cost of 
planned maintenance decreases continuously with the time span. So, sum of two costs has minimum value and the time corresponding to the value is an optimum overhaul cycle. However, this methodology cannot consider reliability reduction according to operation time beyond unit preventative maintenance cycle.

Japan Electricity Association presented a methodology to determine economic maintenance cycle of hydro-electric power equipments[6]. The methodology uses the same concept with Fig. 1.

Fig. 2 presents Vasilevski et al.'s methodology to investigate change of reliability with preventative maintenance cycle in order to determine optimal overhaul cycle and reconstruction time[10]. As shown in Fig. 2, reliability reduction trend vs. operation time is changed with overhaul cycle, re-construction should be carried forward before reliability reaches critical value, and it mean that the overhaul cycle has to be adjusted as late as possible to be re-constructed. But, this study didn't present the method to set up critical failure probability and didn't consider economic efficiency so has practical problem.

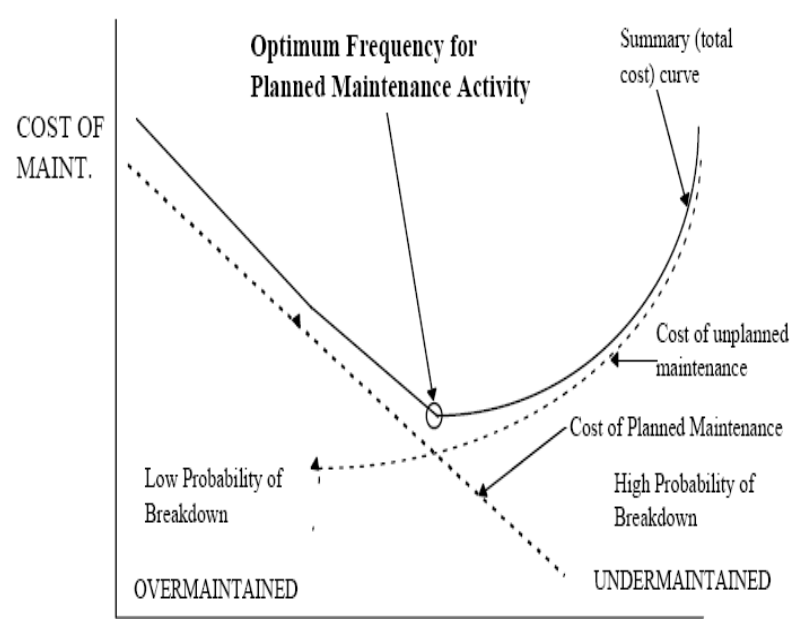

TIME SPAN BETWEEN PLANNED ACTIVITY
Fig.1 Maintenance cost optimization curve of Snowy Mountains Hydro-electric Authority[9].



Fig.2 Vasilevski's methodology to determine optimal overhaul cycle and re-construction time[10].

EPRI TR-111488 presented outline of SRCM(streamlined reliability-centered maintenance) program for hydroelectric power plants instead of RCM(reliability-centered maintenance) that requires huge amounts of data and information[11]. EPRI TR-114160[12], which is a followup report of EPRI TR-1114888, presented three key factors(sound/cost-effective SRCM process, a software tool to manage consistently/effectively SRCM data and project management/working culture change) to succeed in performing SRCM and explained requirements for three key factors. However, purpose of the EPRI studies[11, 12] isn't optimization of overhaul cycle but deduction of preventative maintenance tasks for reliability improvement. 


\section{Methodology to Optimize Overhaul Cycle}

Based on the review results of previous studies, this paper presents a methodology to optimize overhaul cycle considering both reliability and economic efficiency. Basic assumptions are used to develop the methodology as follows:

Reliabilities of component and system should be drastically increased by A class preventative maintenance(overhaul).

O In cases of subcomponents or components applied only to B class preventative maintenance, effect of B class preventative maintenance on reliabilities of component/ system is insignificant.

Fig. 3 depicts overall flow chart of process to optimize overhaul cycle of pumped-storage power equipments. As depicted in the figure, item "task selection and comparison" of the RCM/SRCM methodology is removed because purpose of the methodology is to determine optimal overhaul cycle. Also, FFA(functional failure analysis) is performed including in FMEA(failure modes and effects analysis). Overall process consists of selection of target subcomponents/components, derivation of aging related damage mechanisms for the target subcomponent/components FMEA, calculation of repair/ replacement years, planning of preventative maintenance scenario, reliability analysis, economic efficiency analysis, and derivation of optimal overhaul cycle.



Fig.3 Overall flow chart of process to optimize overhaul cycle of pumped-storage power equipments.

Fig. 4 presents flow chart to select the target subcomponent and components. As presented in the figure, the subcomponents and components subject only to B class preventative maintenance are exclude from target in accordance with the basic assumption about effect of B class preventative maintenance on reliability. Fig. 5 shows flow chart to derive the aging related damage mechanisms for the target subcomponent and components.

Fig. 6 depicts flow chart of FMEA process. First, effect of each damage mechanism on intended function (e.g. structural integrity or performance) of subcomponent is evaluated. Second, based on the evaluation results, effect of the damage occurred on subcomponent on 
component/system is evaluated. Third, next step, check whether subcomponents or components can be repaired or replaced during B class preventative maintenance or not. Last, if repair or replacement is impossible during B class preventative maintenance, draw up a final list of the relevant aging damage mechanisms for the target subcomponents/components.

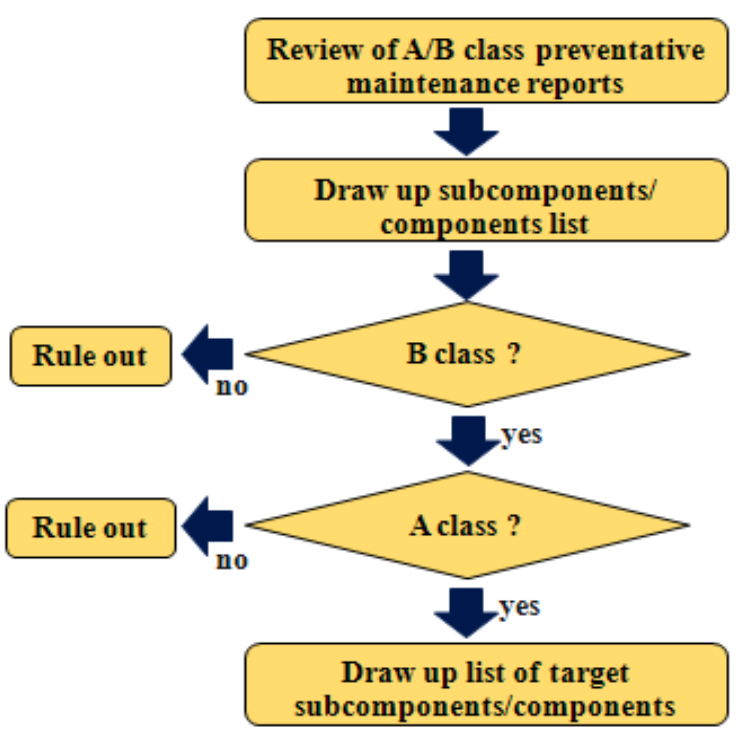

Fig. 4 Flow chart to select target subcomponents and components.

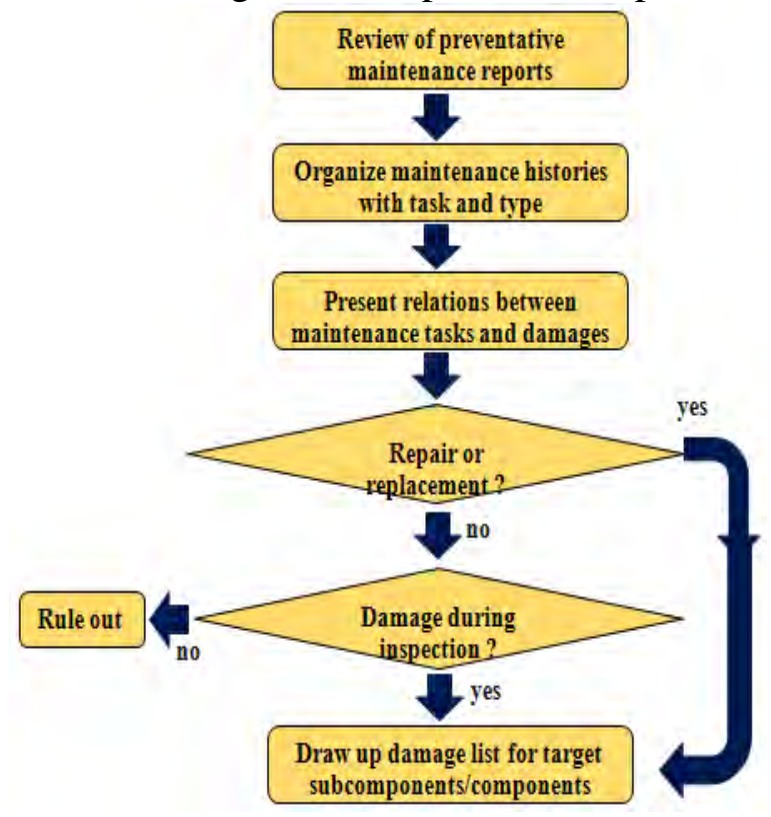

Fig. 5 Flow chart to derive the aging related damage mechanisms for the target subcomponents/components.

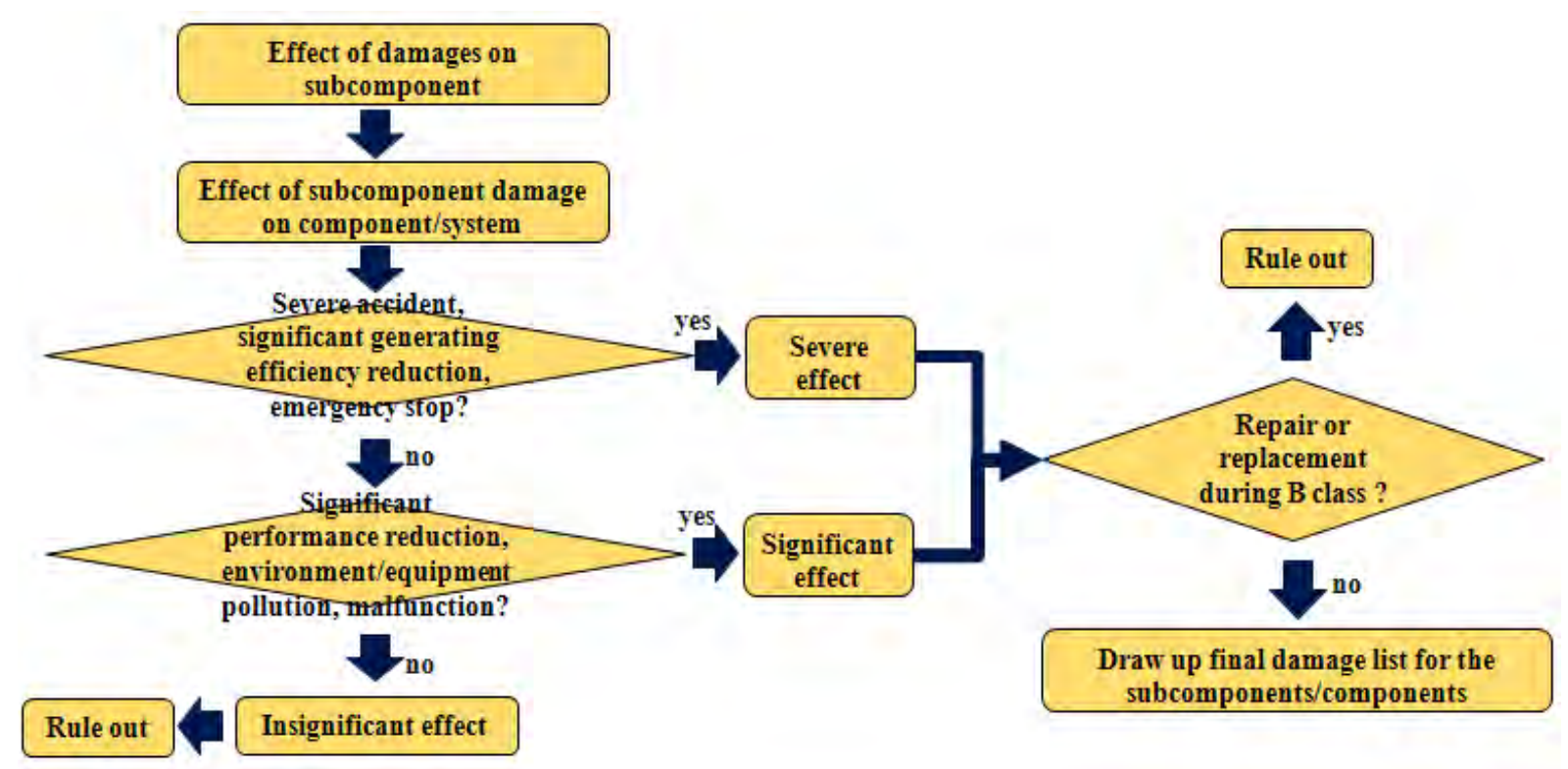

Fig. 6 Flow chart of FMEA.

Analyzing A and B class preventative maintenance histories for the final list derived via the process presented in Fig. 6, real repair/replacement cycles(minimum/mean) for the subcomponent-damage mechanism are derived. These repair and replacement cycles are used as an input for derivation of $\mathrm{CHRF}$ (cumulative hazard rate function) coefficients. 
A preventative maintenance scenario has to be prepared because reliability has variation with order of maintenance class and number within unit cycle. For example, A-B-A, A-B-B-A, AB-B-B-A, etc.

Fig. 7 shows flow chart of reliability analysis. If repair and replacement data are enough to evaluate, CHRF coefficients of equation (1) are directly derived via the numerical analysis using the repair and replacement cycles.

$$
\begin{aligned}
& H(t)=a_{0}+a_{1} t+a_{2} t^{2} \\
& R(t)=\exp (-H(t)) \\
& F(t)=1-R(t)
\end{aligned}
$$

where $H(t)$ is CHRF, $R(t)$ is reliability function, $F(t)$ is $\mathrm{CDF}$ (cumulative damage function) for failure time. If repair and replacement data are not enough to evaluate, CHRF coefficients are derived by using real repair/replacement data, reference reliability curve[14] or database[15], and Bayesian updating technique.

Finally, the overhaul cycle to derive minimum CPUT(cost per operating unit time) value at the target period is determined as an optimal overhaul cycle. CPUT for each preventative maintenance scenario is calculated by equation (4).

$$
C P U T(t)=\frac{t_{y}\left[C_{p} R_{\min }+C_{U}\left(1-R_{\min }\right)\right]}{t \int_{0}^{t_{p}} R(s) d s}
$$

where $C_{p}$ is preventative maintenance cost, $C_{u}$ is post-accident preservation cost, $t_{p}$ is unit cycle time, $t$ is target period of scenario, $R_{\min }$ is minimum reliability within unit cycle.

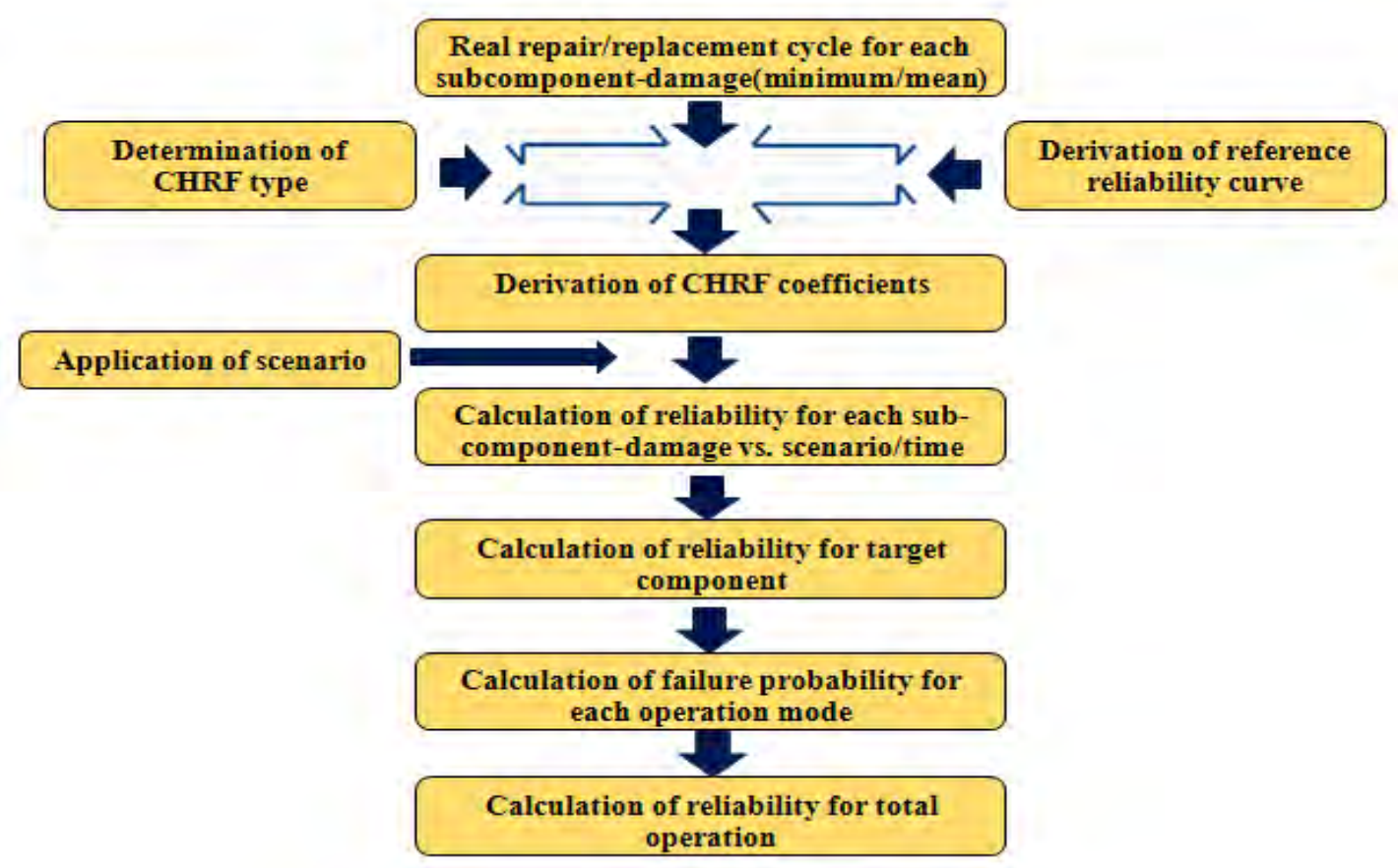

Fig. 7 Flow chart of reliability analysis. 


\section{Application Results}

Table 2 presents overview of a pumped-storage power plant for application of the developed optimization methodology.

Table 2 Overview of a pumped-storage power plant for application of the methodology.

\begin{tabular}{|c|c|c|c|c|}
\hline \multicolumn{2}{|c|}{ Items } & Unit & Generation & Pumping \\
\hline \multicolumn{2}{|c|}{ Operating time } & years & \multicolumn{2}{|c|}{24} \\
\hline \multicolumn{2}{|c|}{ Capacity } & MW & $300 \times 2$ & $370 \times 2$ \\
\hline \multirow{3}{*}{$\begin{array}{l}\text { Pump } \\
\text { turbine }\end{array}$} & Type & - & \multicolumn{2}{|c|}{ Francis } \\
\hline & Max/min. head & $\mathrm{m}$ & $345 / 288$ & $355 / 310$ \\
\hline & Max. output & $\mathrm{kW}$ & 310,000 & 370,000 \\
\hline Generator/ & Type & - & \multicolumn{2}{|c|}{ Vertical Inductive } \\
\hline \multirow[t]{2}{*}{ Motor } & Output & $\mathrm{kVA}$ & 335,555 & 294,752 \\
\hline & Voltage/cumrent & $\mathrm{kV} / \mathrm{A}$ & $18 / 10,763$ & $18 / 10,763$ \\
\hline \multirow[t]{4}{*}{ Ponymotor } & Type & - & - & Vertical Inductive \\
\hline & Output & $\mathrm{kW}$ & - & 12,000 \\
\hline & Revolution speed & $\mathrm{rpm}$ & - & 300 \\
\hline & Voltage/current & V/A & - & $6,600 / 1,712$ \\
\hline
\end{tabular}

Fig. 8 depicts variation of reliability vs. time for various overhaul cycles of scenario 1(A-B-BA). As depicted in the figure, reliability decreases continuously with time but increases after $\mathrm{B}$ or A class preventative maintenance. It is identified that improvement of A class is greater than B class in the viewpoint of reliability. Also, the overhaul cycle becomes longer, reduction degree of reliability is greater.

Fig. 9 shows CPUT variation vs. target operating time after the first overhaul completion for various overhaul cycles of scenario 1. As shown in the figure, the target operating time increases, CPUT value decreases irrelevantly to overhaul cycle. It is identified that CPUT has a minimum value at overhaul cycle, 7.5years when the target operating time for scenario 1 is more than 10 years. In other words, if the target operating time for scenario 1 is more than 10 years, optimal overhaul cycle is 7.5years. As a result of application of the methodology to an aged pumped-storage power plant in South Korea, the overhaul cycle has been extended from 4 years to $7.5 y e a r s$.

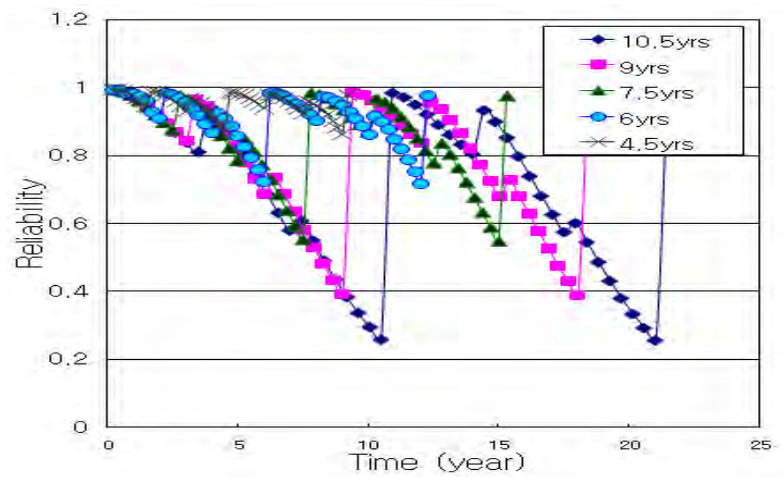

Fig. 8 Reliability of unit vs. time according to various overhaul of scenario 1.

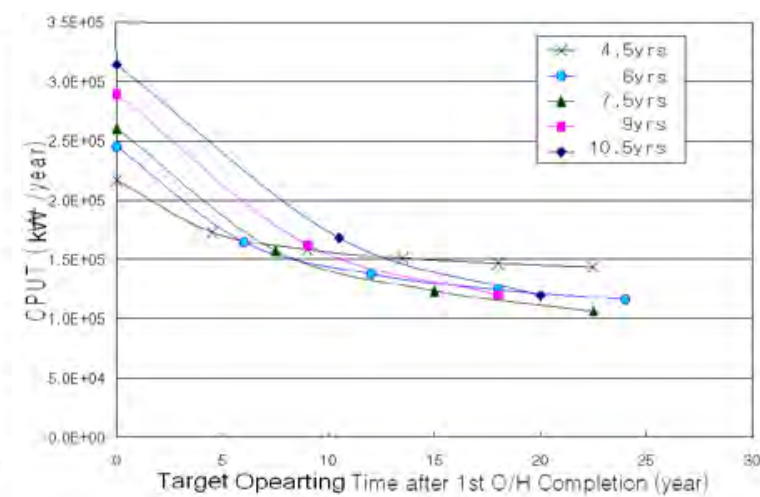

Fig. 9 CPU of unit vs. target time according to various overhaul cycles of scenario 1.

Table 3 presents CPUT variation according to replacement of principal components such as runner and generator. From the table, it is found that generator replacement has greater effect than runner replacement. When replaced with the runner and the generator to bring more economic benefits. 
Table 3 CPUT variation according to replacement of runner and generator.

\begin{tabular}{ccccc}
\hline Component & Nothing & Runner & Generator & Runner \& Generator \\
\hline \hline CPUT(kW/year) & $1.2349 \times 10^{5}$ & $1.1611 \times 10^{5}$ & $1.1352 \times 10^{5}$ & $1.0491 \times 10^{5}$ \\
\hline
\end{tabular}

Note) Scenario 1, Overhaul cycle: 7.5years, Target operating time: 15years

\section{Conclusions}

From the study to optimize overhaul cycle of pumped-storage power plants, the following findings are derived:

As a result of this investigation, it is possible to extend the A class preventative maintenance cycle of pumped-storage power plants in South Korea.

A methodology to optimize the preventative maintenance cycle based on the reliability and economic efficiency is presented, which can investigate variation of reliability and economic efficiency of generating unit vs. overhaul cycle.

$\bigcirc$ As a result of application of the methodology to an aged pumped-storage power plant in South Korea, the overhaul cycle has been extended from 4 years to 7.5years.

$\bigcirc$ When replaced with the runner and the generator to bring more economic benefits.

\section{Acknowledgments}

This work has been supported by KESRI-09310, which is funded by Korea Western Power Co. Ltd. and KHNP(Korea Hydro and Nuclear Power) Co., Ltd.

\section{References}

[1] http://news.naver.com/main/read.nhn?mode=LSD\&mid=sec\&sid1=0000070659.

[2] J.S. Kim, et al., Transaction of KSME, A, Vol.33, No.10, pp.1171-1176.

[3] Korea Western Power Co., Ltd., 2009, Planning Report to Optimize Preventative Maintenance of Pumped-Storage Power Plant.

[4] Korea Hydro \& Nuclear Co., Ltd., 1976 2006, Electricity Generation Chronicles.

[5] K-Water, 2008 2010, Electricity Generation Chronicles.

[6] Japan Electricity Association, 2004, Investigation on Diagnosis Methods and Measures for Aging of Hydro Turbine.

[7] J.S. Kim, 2009, Overseas Business Trip Report for Investigation on Preventative Maintenance Situation of Japan Pumped-Storage Power Plant.

[8] EPRI, 1991, EPRI GS-7325.

[9] http://www.strategicorp.com/news\%20case\%20studies / rcm01.pdf.

[10] A.G. Vasilevski, et al., 1995, Power Technology and Engineering, Vol.29, No.1.

[11] EPRI, 1998, EPRI TR-111488.

[12] EPRI, 1999, Guidelines for RCM in the Hydro Power Industry, EPRI TR-114160.

[13] http://www.pinnaclesystems.us/solutions/manuf-reliability-mro-solutions/rcm-turbo.

[14] USACE, 1998, IWR Report 98-R-6.

[15] IEEE, 1984, IEEE Standard Reliability Data for Pump and Drives, Valve Actuators, and Valves, ANSI/IEEE Std 500-1984 P\&V. 